\title{
The impact of a multimodal/hybrid design on student learning in a diabetes pharmacotherapy series for third professional year pharmacy student population
}

\author{
B. DeeAnn Dugan, John Thomas, Jeffrey A. Kyle \\ McWhorter School of Pharmacy, Samford University, USA
}

\author{
Keywords \\ Active learning \\ Diabetes \\ Hybrid design \\ Pharmacy student \\ Correspondence \\ B. DeeAnn Dugan \\ Department of Pharmacy Practice \\ McWhorter School of Pharmacy \\ Samford University \\ 800 Lakeshore Drive \\ Birmingham, AL 35229 \\ United States of America \\ bdugan@samford.edu
}

\begin{abstract}
Introduction: Over the last several years, pharmacy education has been moving towards a blended/hybrid model of learning. The purpose of this study was to evaluate the impact of a hybrid, multi-modal design in a diabetes sequence. Method: A diabetes series was converted from a lecture-based to a hybrid design. Percentage scores from Exam 1 and Final exam questions compared a control cohort to different cohorts over two years. Primary outcome measure was student scores. Results: The score difference on Exam 1 between the 2015 and 2017 cohorts was -6.69 ( $p=0.19$ ). Comparison of 2016 and 2017 showed a $-5.13 \%(p=0.33)$ score change. An 8.6-point improvement in Final exam scores was observed. Both hybrid model cohorts scored higher on questions related to insulin titration and treatment selection. Conclusion: No change in knowledge acquisition using the hybrid multi-modal design was seen; however there an improvement in knowledge retention was observed.
\end{abstract}

\section{Introduction}

For many years, traditional lectures have been the mainstay of pharmacy education delivery (Abate et al., 2000; DiPiro et al., 2009;). The passive nature of learning in this instructional method has received criticism as the average length of lectures exceeds adult learners' attention spans, or do not enhance students' ability to problem solve and think critically (Blouin et al., 2008; Shah et al., 2013). In a position paper, Zorek and colleagues argued for the importance of limiting the amount of information delivered to students and the adoption of more innovative educational approaches (Zorek et al., 2010). Active learning is one of the approaches which has evolved in response to this.

Active learning is defined as 'a process whereby students engage in activities, such as reading, writing, discussion, or problem solving that promotes analysis, synthesis, and evaluation of class content.' (Center for Research and Learning, n.d.). Examples of active learning approaches include group discussion, think-pair-share, cooperative groups, peer review, case studies, active review, jigsaw discussion and clicker-based quizzes. Active learning in pharmacy education has spread and been implemented in multiple areas. In 2011, a study found that $87.0 \%$ of the 114 pharmacy schools in the United States included in the study, used active learning techniques in their classrooms (Steward et al., 2011). Much of pharmacy education has been moving towards a blended or hybrid model of learning over the past several years; this is in part because of the evidence showing its benefits (McLaughlin et al., 2015). One study showed higher scores on a test of longterm retention when studying antimicrobial stewardship 
(Macdougall, 2017). Another study showed an increase in the student retention level for pharmacotherapy content taught using active learning techniques during advanced pharmacy practice experiences (APPEs) (Lucas et al., 2013).

Hybrid and/or blended models of teaching have been implemented in many pharmacy education areas from basic science and pharmacokinetics to inpatient and outpatient therapeutics (Crouch, 2009; Edginton \& Holbrook, 2010; Phillips, Schumacher \& Arif, 2016; Prescott et al., 2016; Sancho et al., 2006; Wanat, Tucker, \& Coyle, 2016; Zapantis et al., 2008). It can be challenging, however, to design an active learning-based class that balances the time requirements and connects pre-class and in-class learning activities (Khanova et al., 2015). While current evidence supports the use of hybrid models, the most appropriate use of these instructional methods in terms of student experience and/or skill, classroom size, and instructor experience remain largely unknown (McLaughlin et al., 2015; Margolis, Porter, \& Pitterle, 2017; Rotellar \& Cain, 2016). The purpose of this study was to evaluate the impact of a hybrid, multi-modal design of a diabetes lecture sequence. The primary endpoint of this study was to evaluate the impact on student learning compared to previous years. A secondary endpoint was to determine whether instructor changes to instructional methods in year two in the diabetes module improved student learning and satisfaction compared to year one of the course.

\section{Methods}

The classroom-based diabetes pharmacotherapy series of instruction is taught over 12 contact hours in the autumn term of the third professional year as part of a pharmacotherapy sequence. Prior to 2016, the diabetes series was delivered primarily via lectures which incorporated short case vignettes and targeted patient cases. In 2016, the instructor changed the pedagogical model to a blended, multi-modal design. This design was continued in 2017; however, two activities were changed, and additional guidance was provided to students in response to instructor course evaluations from the 2016 cohort. Table I summarises the diabetes sequence design elements for 2015 to 2017 while a complete description is provided below.

Pharmacy Series Design in 2015: In-class instruction included 240 Microsoft PowerPoint lecture slides; of those, 106 focused on type 1 Diabetes (DM) and 132 on type 2 DM. Accompanying these lectures were 17 focused patient cases and three short patient vignettes. In addition, approximately two hours of video lecture, 86 Microsoft
PowerPoint slides in total, about medication were provided. All lecture slides, including video lectures, and patient cases were directly tied to series learning objectives.

Series Design in 2016: A blended, multimodal model was implemented. The model provided six mini lectures of approximately 16 Microsoft PowerPoint slides per mini lecture. Total slide number for all mini lectures was 106. In addition to the mini lectures, students were required to view four video lectures on medications totalling 80 PowerPoint slides. Multiple activities were incorporated to teach material discussed in mini lectures as well as expand content application. Activities included: focused patient cases, practice worksheets on insulin dosing and conversion, renal dosing, adverse drug reactions and medication counselling, an activity on medication selection factors, and a Jigsaw activity for the American Diabetes Association (ADA) Standards of Care in Diabetes. All elements, lectures, cases, and activities were directly tied to series learning objectives which were unchanged from 2015.

Series Design in 2017: A blended, multimodal model was continued, however, based on student feedback a guidance document was created to assist students in knowing what needed to be done prior to class, what to bring to class, and what was due at the end of class. Additionally, two activities, Jigsaw Standard of Care and Medication Adverse Reactions, Counselling and the Renal dosing worksheet, were changed based on student feedback and 2016 exam scores. Video lecture lengths were decreased to 1.5 hours, which included the addition of content related to individualising goals (See Table I for more details). The number of mini lectures were reduced from six to four with an average of 19 Microsoft PowerPoint slides per mini lecture. The total number of slides were 77. Lastly, to assist students studying, 'Before you go' slides were added at the end of each mini lecture and activity. Series objectives remained unchanged from previous years. Table II is a description of the pedagogical methods used in each cohort.

\section{Data analysis}

To compare initial knowledge acquisition and subsequent retention, exam scores using the same 21 questions from Exam 1 and nine questions from the Final Exam, were used. Using 2015 as a control, Exam 1 and Final Exam scores in 2016 and 2017 were compared to assess the impact of the blended, multimodal instructional model. To determine if the changes made to the model in 2017 improved the student learning, 2016 Exam 1 and Final Exam scores were compared to those in 2017. All 


\section{Table I: Diabetes Sequence Instructional Design}

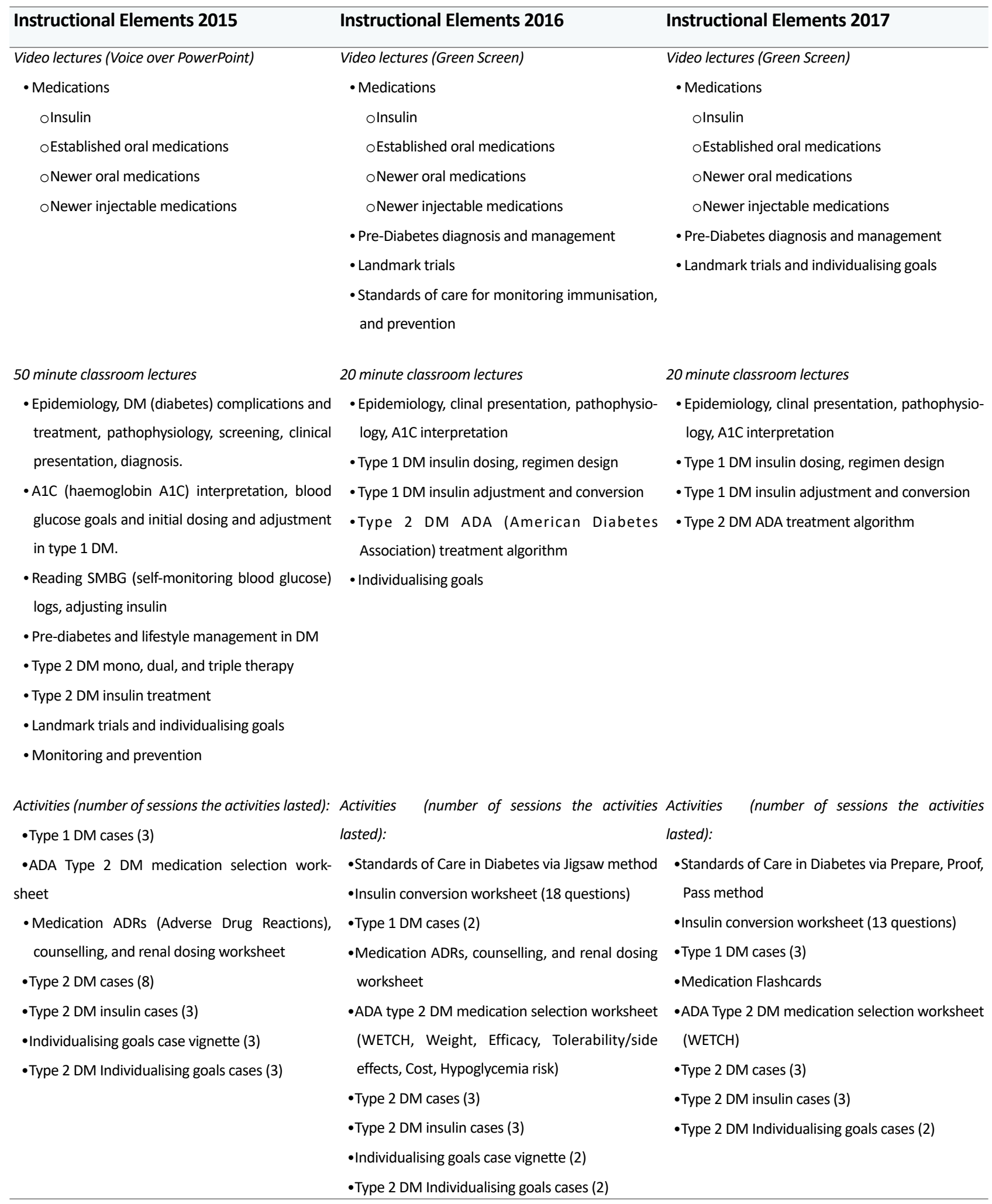




\section{Table II: Pedagogical Method Descriptions}

Method
Worksheet on Adverse Drug Reactions
(ADRs), Counselling and Renal dosing
Type 2 cases
Brief case vignette on patient goals

Classroom-based lecture

Type 1 cases

Extra practice vignettes

Video Lecture

Mini lecture

WETCH

Standards of Care (Jigsaw Method)

\section{Description}

For each medication class, students listed common side effects, severe side effects, precautions and contraindications, common counselling points, and as applicable, renal doses.

Cases provided subjective and objective information. Students were required to use this to assess the patient case and create a plan. Work was done individually and in groups for seven minutes followed by an eight minute class discussion.

Short scenarios with targeted information were read to the class. The class then indicated the most appropriate goal via a shout out to the instructor.

A PowerPoint slide set presentation, generally 50 to 60 minutes in length.

Cases provided subjective and objective information. The students were required to use this to assess the patient case and create a plan. The plan required calculations to determine initial doses, conversion from one insulin to another, and/or adjustment of a dose. The work was done individually and in groups over seven minutes, followed by an eight minute class discussion and instructor demonstration of calculations.

Focused mini cases to assist students reading blood glucose logs and determine which insulin should be adjusted.

PowerPoint slide set presentation provided either in a Voice over PowerPoint format or with the use of a green screen.

PowerPoint slide set presentation generally 20 minutes or less, in length.

For each medication class, students categorised medication's effect on weight, risk of hypoglycemia, significant side effects, contraindications and precautions, and tolerability issues such as whether the medication is oral or injectable, A1C efficacy, and cost to the patient.

Jigsaw Method: In groups of four, each student was asked to read a section of seven to ten pages in the ADA guidelines, answer questions provided by the instructors on the content, and then teach the section to their group members.

Prepare, Proof, Pass Method: Modification of the Jigsaw method. Students, in groups of four or five, were assigned a section of the ADA guidelines. Students then answered instructor provided questions on the content and then Standards of Care (Prepare, Proof \& sent their answers to teammates to proof their work. Each member prepared a section, share their section, and Pass ) check all sections from their group members.

Insulin calculation worksheet Covered initial dosing of bolus insulin using 2/3 and 50:50 rules. The worksheet required students to convert one basal insulin formulation into another formulation. For example: converting NPH dosed twice daily to Lantus.

Students, working in groups of four or five, prepared flashcards to assist their learning about common doses, side effects, precautions, contraindications, and clinical pearls of the medications. 
questions from Exam 1 and the Final Exam were mapped to corresponding learning objectives and pedagogical activities and can be found in Table III.

To assess qualitatively, students were given a Qualtrics survey covering the learning influence of the lesson design, activities, mini-lectures, and formative feedback methods utilised. The survey used a four-point Likert scale as well as questions requiring students to rank and give a star rating of their impressions of how much activities contributed to their learning and/or their satisfaction with the hybrid, multimodal learning design. Completion of the anonymous survey was incentivised through a gift card drawing. This study was approved by the Samford University Institutional Review Board.

To protect student confidentiality, percent cumulative question averages were collected from ExamSoft generated reports for the primary and secondary measures. A two-sided paired T-Test and Chi square tests were used to assess for significance using Microsoft Excel software. To adjust for multiple comparisons, the Bonferroni correction was used. For the unadjusted statistical analysis, an alpha value of $<0.05$ was used. For the Bonferroni adjusted analysis, and alpha value of < 0.001 was used. Survey responses for specific activities were matched to exam questions and analysed.

\section{Results}

All three cohorts were similar in makeup in their entering GPA for the course, and GPA upon entering the diabetes sequence in the autumn of the third professional year. For all three cohorts used in this study (2015, 2016, and 2017), there were 370 students who had scores on Exam 1 and 369 students who had scores on the Final Exam. Participant demographics are shown in Table IV.

\section{Table IV: Baseline Demographics}

\begin{tabular}{llll}
\hline & $\mathbf{2 0 1 5}$ & $\mathbf{2 0 1 6}$ & $\mathbf{2 0 1 7}$ \\
\hline Male (\%) & 28.5 & 39.6 & 38.2 \\
$\begin{array}{l}\text { Female (\%) } \\
\text { Average Admis- }\end{array}$ & 71.5 & 60.4 & 61.8 \\
$\begin{array}{l}\text { sion GPA } \\
\text { Average Enter- }\end{array}$ & 3.45 & 3.42 & 3.32 \\
$\begin{array}{l}\text { ing Fall P3 GPA } \\
\text { Prior BA or BS }\end{array}$ & 3.287 & 3.284 & 3.261 \\
(\%) & 38.9 & 24.0 & 21.5 \\
\hline
\end{tabular}

Exam 1: The percentage score difference for Exam 1 between the $2015(n=134)$ and $2016(n=107)$ cohorts was $-1.32 \%(p=0.73)$ and the difference between 2015 and $2017(n=129)$ cohorts was $-6.69 \%(p=0.19)$. The 2016 and 2017 comparison revealed a $-5.13 \%(p=0.33)$ change in score percentages indicating stronger performance by the 2016 cohort versus the 2017 cohort. Data indicates some activities were more effective than others, although few activities were improved compared to 2015 for both 2016 and 2017. Activities which were associated with improved student scores compared to the 2015 control group were: the insulin worksheet, WETCH (Weight, Efficacy, Tolerability/side effects, Cost, Hypoglycaemia risk), and vignettes with mini lecture related to individualising A1C (haemoglobin A1C) goals. The Standards of Care activity, both using the Jigsaw method in 2016 or the Prepare, Proof, Pass method in 2017, was associated with lower scores in the 2016 and 2017 groups compared to the 2015 cohort as was the 2017 Medication Flashcard activity. Video lecture in either the Voice over PowerPoint (VoPP) or Green Screen (GS) formats appears to have been equally effective as classroom-based lecture for the 2016 cohort; however, it was less effective for the 2017 cohort. See Table V for a listing of Exam 1 student scores and comparison $p$ values.

Final Exam: The percent score differences were 8.32, 8.77, and 0.44 between $2015(n=135)$ and $2016(n=$ 108) with $p=0.22,2015$ and $2017(\mathrm{n}=126)$ with $p=$ 0.18 , and 2016 and 2017 with $p=0.73$, respectively. The 2016 and 2017 groups both scored higher on questions related to insulin titration and conversion and treatment selection in patients with type 2 DM. Additionally, the 2017 cohort scored higher than 2015 or 2016 on complication treatment. All cohorts scored high on insulin initiation. Looking at the associated learning activities, it appears the insulin worksheet activity and medication selection activity (WETCH) were associated with improved retention of content compared to classroom-based lecture. See Table VI for a listing of student final exam scores and comparison $p$ values.

Survey results can be found in Table VII and Figures I through III. Table VII contains student survey responses. Figure I shows the responses of students asked to rate how greatly each of the activities contributed to their learning. A response of 1 star corresponded to a low impact and 5 stars a high impact. Overall, 38.3\% of students completed the survey in 2016, 65.1\% completed it in 2017. Surveys given in 2016 and 2017 
Table V: Exam 1 Scores

\begin{tabular}{|c|c|c|c|c|c|c|c|}
\hline $\begin{array}{l}\text { Question } \\
\#\end{array}$ & $2015 \%$ Correct & $2016 \%$ Correct & 2017 \% Correct & $\begin{array}{l}2015 \text { versus } 2016 \\
p \text { value }\end{array}$ & $\begin{array}{l}2015 \text { versus } 2017 \\
p \text { value }\end{array}$ & $\begin{array}{l}2016 \text { versus } 2017 \\
p \text { value }\end{array}$ & $\begin{array}{l}2016 / 2017 \\
\text { Combined } p \text { value }\end{array}$ \\
\hline 1 & 66.5 & 60.7 & 89.1 & 0.36 & $<0.001$ & $<0.001$ & - \\
\hline 2 & 68.6 & 83.2 & 65.1 & 0.01 & 0.54 & 0.001 & - \\
\hline 3 & 61.2 & 93.5 & - & $<0.001$ & - & - & - \\
\hline 4 & 91.7 & 86.0 & - & 0.15 & - & - & - \\
\hline 5 & 68.6 & 82.2 & 65.1 & 0.02 & 0.54 & 0.003 & - \\
\hline 6 & 94.1 & 91.6 & - & 0.46 & - & - & - \\
\hline 7 & 85.1 & 86.0 & 72.9 & 0.84 & 0.02 & 0.01 & - \\
\hline 8 & 86.6 & 62.6 & 79.8 & $<0.001$ & 0.14 & 0.003 & - \\
\hline 9 & 94.8 & 89.7 & 64.3 & 0.14 & $<0.001$ & $<0.001$ & $<0.001$ \\
\hline 10 & 99.3 & 80.4 & 91.5 & $<0.001$ & 0.003 & 0.01 & \multirow{2}{*}{-} \\
\hline 11 & 86.6 & 82.2 & 79.1 & 0.36 & 0.11 & 0.54 & \\
\hline 12 & 91.1 & 94.4 & 96.1 & 0.009 & $<0.001$ & 0.53 & $<0.001$ \\
\hline 13 & 83.6 & 90.7 & 83.7 & 0.08 & 0.85 & 0.12 & - \\
\hline 14 & 98.5 & 100 & 100 & 0.2 & 0.16 & 1 & - \\
\hline 15 & 91.7 & 97.2 & 96.1 & 0.07 & 0.14 & 0.65 & - \\
\hline 16 & 74.6 & 60.7 & 78.3 & 0.02 & 0.48 & 0.003 & - \\
\hline 17 & 97.7 & 98.1 & 97.7 & 0.84 & 0.86 & 0.81 & - \\
\hline 18 & 73.1 & 53.3 & - & 0.001 & - & - & - \\
\hline 19 & 82.1 & 85.0 & 80.6 & 0.54 & 0.76 & 0.37 & - \\
\hline 20 & 93.2 & 80.4 & 75.2 & 0.002 & $<0.001$ & 0.34 & $<0.001$ \\
\hline 21 & 83.6 & 76.6 & 62.0 & 0.18 & $<0.001$ & 0.02 & 0.0016 \\
\hline Average & & & & & & & \\
\hline $\begin{array}{l}\text { total } \\
\text { correct } \\
\text { answers }\end{array}$ & 84.0 & 82.6 & 65.6 & 0.73 & 0.33 & 0.19 & - \\
\hline
\end{tabular}

Table VI: Final Exam Scores

\begin{tabular}{|c|c|c|c|c|c|c|}
\hline Question \# & $2015 \%$ Correct & $2016 \%$ Correct & $2017 \%$ Correct & $\begin{array}{l}2015 \text { versus } 2016 \\
p \text { value }\end{array}$ & $\begin{array}{l}2015 \text { versus } 2017 \\
p \text { value }\end{array}$ & $\begin{array}{l}2016 \text { versus } 2017 \\
p \text { value }\end{array}$ \\
\hline 1 & 95.6 & 97.2 & 97.6 & 0.49 & 0.36 & 0.85 \\
\hline 2 & 30.4 & 26.9 & 53.2 & 0.55 & $<0.001$ & $<0.001$ \\
\hline 3 & 96.3 & 94.4 & 92.1 & 0.49 & 0.14 & 0.47 \\
\hline 4 & 64.9 & 66.7 & 78.6 & 0.72 & 0.01 & 0.04 \\
\hline 5 & 65.2 & 85.2 & 79.4 & $<0.001$ & 0.01 & 0.25 \\
\hline 6 & 67.4 & 78.7 & 77.8 & 0.05 & 0.06 & 0.86 \\
\hline 7 & 93.3 & 85.2 & 84.1 & 0.04 & 0.02 & 0.82 \\
\hline 8 & 35.5 & 88.0 & 86.5 & $<0.001$ & $<0.001$ & 0.74 \\
\hline 9 & 74.1 & 67.6 & 72.2 & 0.27 & 0.74 & 0.44 \\
\hline \multicolumn{7}{|l|}{ Average } \\
\hline $\begin{array}{l}\text { total } \\
\text { correct } \\
\text { answers }\end{array}$ & 69.1 & 76.6 & 80.2 & 0.80 & 0.18 & 0.73 \\
\hline
\end{tabular}


show that students strongly agreed/agreed that the WETCH, insulin activity, cases, video lectures and minilectures contributed to their learning (see Table VII).

Table VII: Percentages of students who strongly agree/ agree that the methods contributed to their learning of the material

\begin{tabular}{llc} 
Survey Question & \multicolumn{2}{c}{ Percentage } \\
& $\mathbf{2 0 1 6}$ & $\mathbf{2 0 1 7}$ \\
Mini lectures & 92.7 & 82.7 \\
Video lectures & 80.5 & 74.7 \\
Patient cases & 92.7 & 93.8 \\
WETCH activity & 82.9 & 91.4 \\
Insulin worksheet & 78.1 & 86.4 \\
Standards of Care activity & 41.5 & 38.3 \\
Medication Flashcards activity & & 27.2 \\
Working with Team & 9.8 & 40.74
\end{tabular}

The change in score from 2015 to 2016 and from 2016 to 2017 for the insulin activity was positive, which correlates to the $86.4 \%$ agreeing it contributed to their learning and the mean rating of 4.08 out of 5 stars (Table VII and Figure I). The patient cases were perceived as contributory among $92.5 \%$ of students. The cases were also ranked as more important by slightly over half of students, see Figure II, receiving 4.30 out of 5 stars with only $3.8 \%$ of students ranking them low. The video lectures were perceived as potentially contributing to learning by most students with $41.3 \%$ ranking it as an important learning method. While $79.7 \%$ of students felt the amount of time to complete the videos was appropriate, the $20.3 \%$ who indicated the amount of time was not appropriate commented they felt it encroached on out of class time and preferred the material be covered in lectures.

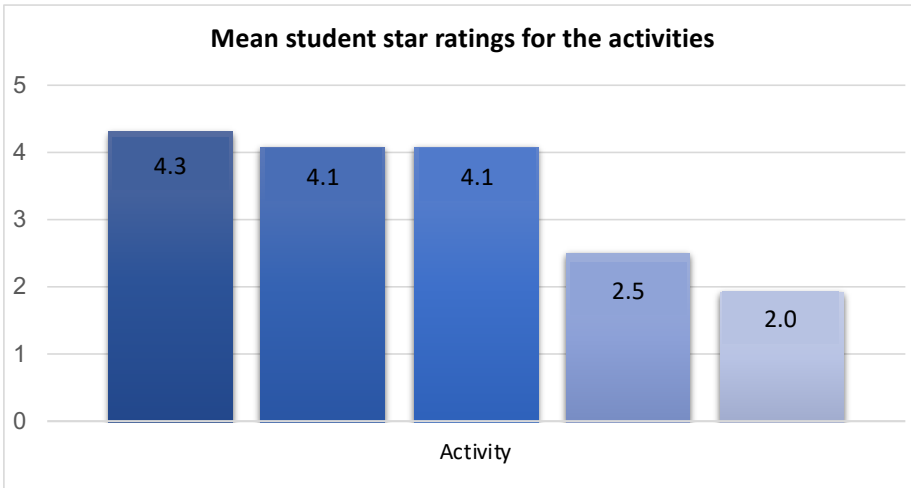

- Patient Cases $\square$ Insulin Activity $\square$ WETCH $\square$ Standards of care $\square$ Med Flashcards

Figure I: Student star ratings for the activities

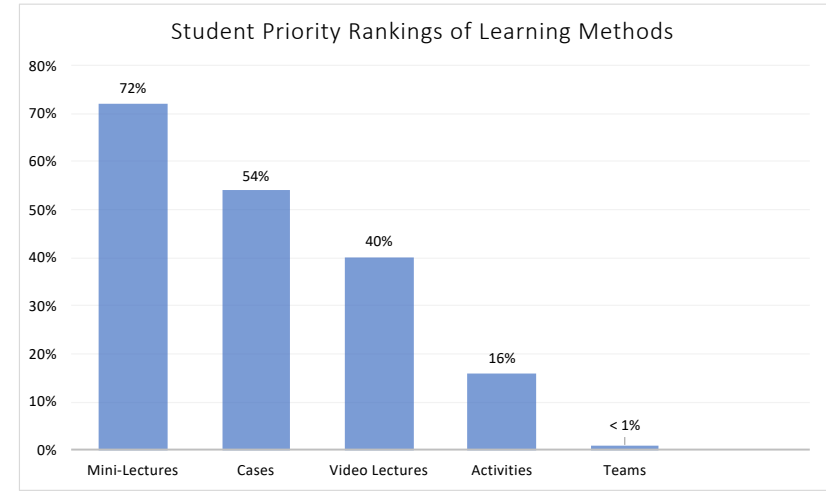

Figure II: Student perception on learning methods, priority ranking by importance

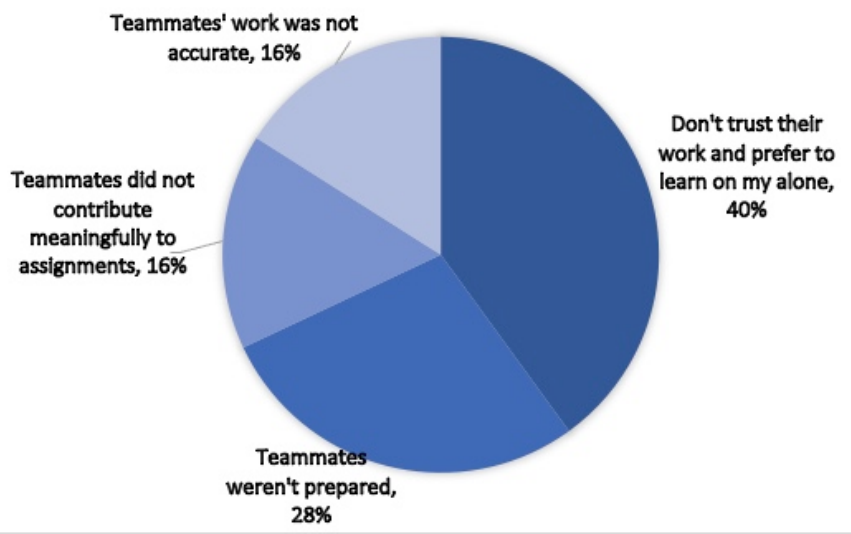

Figure 3-2017 Student Cohort perceptions on reasons working in teams did not contribute to learning

The Medication Flashcards activity and working with teams were rated much lower by students. Survey data indicated $72.8 \%$ of students scored disagree/strongly disagree for the impact Medication Flashcards had on their ability to learn the information. The Medication Flashcard activity received the lowest rating with a mean of only 1.91 stars. The WETCH, insulin activity, and patient cases all received ratings of four stars or higher.

Use of teams in the hybrid model was not perceived as beneficial by students. While over half of students indicated they enjoyed working in the teams and $86.3 \%$ of students indicated that they strongly agree/agree when asked if all team members effectively contributed to the team. Only $9.8 \%$ of students in 2016 and $40.7 \%$ of students in 2017 perceived teams as contributing to their learning with $51.2 \%$ of students in 2016 and $23.5 \%$ of students in 2017 indicating disagree/strongly disagree on this question. Less than one percent of students felt that teams were the most important, while $90.5 \%$ felt teams were less important to their learning. Figure III shows 
response rates as to why the students did not think teams contributed to their learning. Teammates not trusting the work of their other teammates was the top reason, with $56.1 \%$ of students choosing it. In addition, $39.8 \%$ of students responded that teammates were not prepared for tasks.

Less than half of students, $41.5 \%$ in 2016 and $38.3 \%$ in 2017, agreed that the standards of care activity contributed to their learning. Figure I shows a mean rating of 2.51 stars for the standards of care activity.

Students generally felt the design sequencing was logical and made sense. Overall, $61.3 \%$ and $56.3 \%$ of students felt the design kept them engaged and that it contributed to their learning, respectively. The activities were ranked as a less important method by $40.5 \%$ of students. Conversely, $82.5 \%$ agreed that the mini-lectures contributed to their learning and $72.7 \%$ found them to be a more important method of learning.

\section{Discussion}

This study evaluated the effect and student satisfaction and perceptions of a multimodal, hybrid design which utilised flipped and blended learning methods, active learning activities, as well as traditional lectures. In this study neither the matched question average on Exam 1 nor the Final Exam was statistically different between any cohort although students in in the hybrid, multimodal cohorts scored an average of eight points higher on the Final Exam versus the traditional methods control.

Elements of the hybrid, multimodal method, including the insulin activity worksheet, WETCH worksheet, and individualising goals patient vignettes with patient cases, were associated with improved exam scores. While the 2017 group performed better on the Final Exam Standards of Care activity-related questions, this activity was associated with lower scores in both exams for the 2016 cohort as well in Exam 1 for the 2017 cohort. The 2017 group also had lower scores on questions related to the Medication Flashcards activity.

Student surveys indicated students found the design logical and engaging and gave three activities four stars. At the same time, students rated mini-lectures, video lectures, and patient cases as having most contributed to their learning of the content while the activities category was rated second to last. Teams were not perceived as contributing to learning by over $99 \%$ of students.
Published studies show mixed results both with the effectiveness of a flipped model design as well as in student satisfaction with active learning models. Similar to the findings in this study many studies in pharmacotherapy or therapeutics courses found no difference first examination scores when comparing a traditional lecture model with a flipped classroom or team-based learning (TBL) model. McLaughlin evaluated one such conversion (McLaughlin et al., 2015). In this study, online modules were created; however, while students were encouraged to complete them, they weren't required to. Results indicated students in the flipped model scored lower on examinations and student post-test scores, given as part of the TBL model, did not correlate with their examination score. They determined that student preparation of foundational content was important for successful blended learning. Marshall and colleagues also found improvement in pre to post quiz scores; exam scores, however, while not decreasing were not improved (Marshall, Nykamp, \& Momary, 2014). In a 2015 study, Farland and colleagues, also found no difference in initial exam scores, and no difference when a retention exam was given five months later (Farland et al., 2015). In contrast, studies published by Wong (2014) and Pierce (2012) all found the flipped or blended learning model led to improved test scores. Koo and colleagues also saw improved exam scores as well as improvements in pre to post-test scores (Koo et al., 2016). They hypothesised this could be due to poor initial retention of the material by students. This finding is similar to the current study where student exam scores were unchanged for Exam 1. In contrast to these findings, although statistically non-significant, an eight-point score improvement was demonstrated in the Final Exam scores for both multimodal/hybrid design cohorts.

Student survey results also demonstrate this divergence. Several studies report learners liked the flipped/blended classroom model, and rated courses which used it as good to very good (Koo et al., 2016; Marshall, Nykamp \& Momary, 2014; Pierce \& Fox, 2012;). Student perception surveys also demonstrate students believe they learn more from this model than the traditional lecture (Bossaer et al., 2016; Gavaza, Campbell, \& Mullins, 2012; Marshall, Nykamp \& Momary, 2014). In the study by Pierce and Fox, whilst $75.0 \%$ of students thought the flipped classroom model was dissimilar to other courses at the school, $62.0 \%$ of students completing the survey expressed a desire for more classes to use this model (2012). The story of student satisfaction and perception is complex as demonstrated by the results of the student survey in the Gavaza, Campbell, and Mullins study (2012); Their study 
found that $53.4 \%$ of students thought active learning was worthwhile, but with most students disagreeing/strongly disagreeing that it was more effective than lecture. The schism between student perception continues as $26.1 \%$ of students disagreed/strongly disagreed groups were essential to learning while $60.6 \%$ of students simultaneously agreed/strongly agreed active discussion and involvement with other students was essential to learning (Gavaza, Campbell, \& Mullins, 2012). Survey data from other studies also indicates students preferring the traditional classroom model, even when they think they have learned more from the flipped/blended model (Farland et al., 2015). Wong, Lopes and Rojagopalan found that student satisfaction with the flipped/blended model was not improved by better exam scores or student acknowledgement of student understanding (2014). They go on to state that one explanation for this could be the novelty of the design, as other students have shown satisfaction when implementation was done over a longer period of time (Wong, Lopes, \& Rojagopalan, 2014). In the study by Koo and colleagues, students indicated dissatisfaction with the flipped/blended model because they thought workload was too high and the time required was excessive. Koo goes on to postulate that perhaps the discrepancy between liking the flipped/blended model, but disliking the workload and time required could be attributed to needed changes in student study habits (Koo et al., 2016). An analysis by Brown would seem to concur that this could be the case (Brown, 2017).

There are many possible reasons for the contradictory information for both effectiveness as well as student satisfaction, one could be the methods used. A study by Tatachar and colleagues (2016) found that students enjoyment of activities, as well as whether students perceived them as effective, was activity-specific (Tatachar et al., 2016). Certainly, the sequencing and student prior experience of active learning, flipped, and hybrid models are likely contributors to student perceptions of the activity and its effectiveness.

There are several limitations to this study. While the 2015 cohort were used as a control group, and indeed were primarily lecture-based, several active learning strategies, although on a much smaller scale, supplemented the traditional lectures. Additionally, while based on student feedback and exam scores, changes to activities and guidance documents were added to the design between the initial implementation in 2016 and the following cohort in 2017. Although student GPA at admission and upon entering the semester in which the students engaged in the new design were not different, there is evidence the 2017 cohort had some significant learning deficits related to pharmacology. This class scored $39.0 \%$ on pharmacology items which were covered in the previous semester compared to a score of $27.0 \%$ on material which was new on a pre-sequence quiz to assist them in completing a continuing professional development plan. Finally, the 2017 cohort had two pharmacology exams in the ten days the diabetes content was delivered. This likely contributed to lack of preparation for some of the in-class activities which may have resulted in lower exam scores.

\section{References}

Abate, M.A., Meyer-Stout, P.J., Stamatakis, M.K., Gannett, P.M., Dunsworth, T.S., \& Nardi, A.H. (2000). Development and Evaluation of Computerized Problem-based Learning Cases Emphasizing Basic Sciences Concepts. American Journal of Pharmaceutical Education, 64(1), 74-82

Blouin, R.A., Joyner, P.U., \& Pollack, G.M. (2008). Preparing for a Renaissance in Pharmacy Education: The Need, Opportunity, and Capacity for Change. American Journal of Pharmaceutical Education, 72(2), 42. https://doi.org/10.5688/aj720242

Bossaer, J.B., Panus, P., Stewart, D.W., Hagemeier, N.E., \& George, J. (2016). Student Performance in a Pharmacotherapy Oncology Module Before and After Flipping the Classroom. American Journal of Pharmaceutical Education, 80(2), 31. https://doi.org/ 10.5688/ajpe80231

Brown, D. (2017). An evidence-based analysis of learning practices: The need for pharmacy students to employ more effective study strategies. Currents in Pharmacy Teaching and Learning, 9(2), 163-170. https://doi.org/10.1016/i.cptl. $\underline{2016.11 .003}$

Center for Research and Learning. Introduction to Active Learning. (n.d.). Available from: http://www.crlt.umich.edu/ tstrategies/tsal

Crouch, M.A. (2009). An Advanced Cardiovascular Pharmacotherapy Course Blending Online and Face-to-Face Instruction. American Journal of Pharmaceutical Education, 73(3), 1-9

Dipiro, J.T. (2009). Why Do We Still Lecture? American Journal of Pharmaceutical Education, 73(8), 137. https://doi.org/10.5688/ aj7308137

Farland, M.Z., Franks, A.S., Barlow, P.B., Rowe, A.S., \& ChisholmBurns, M. (2015). Assessment of student learning patterns, performance, and long-term knowledge retention following use of didactic lecture compared to team-based learning. Currents in Pharmacy Teaching and Learning, 7(3), 317-323. https://doi.org/ 10.1016/i.cptl.2014.12.009

Edginton, A., \& Holbrook, J. (2010). A Blended Learning Approach to Teaching Basic Pharmacokinetics and the Significance of Face- 
to-Face Interaction. American Journal of Pharmaceutical Education, 74(5), 1-11

Gavaza, P., Campbell, J., \& Mullins, R. (2012). Pharmacy students opinions toward active learning in the didactic curriculum. Currents in Pharmacy Teaching and Learning, 4(4), 273-277. https://doi.org/10.1016/i.cptl.2012.06.002

Khanova, J., McLaughlin, J. E., Rhoney, D. H., Roth, M. T., \& Harris, S. (2015). Student Perceptions of a Flipped Pharmacotherapy Course. American Journal of Pharmaceutical Education, 79(9), 18. https://doi.org/10.5688/ajpe799140

Koo, C.L., Demps, E.L., Farris, C., Bowman, J.D., Panahi, L., \& Boyle, P. (2016). Impact of Flipped Classroom Design on Student Performance and Perceptions in a Pharmacotherapy Course. American Journal of Pharmaceutical Education, 80(2), 33. https://doi.org/10.5688/ajpe80233

Lucas, K.H., Testman, J.A., Hoyland, M.N., Kimble, A.M., \& Euler, M.L. (2013). Correlation Between Active-Learning Coursework and Student Retention of Core Content During Advanced Pharmacy Practice Experiences. American Journal of Pharmaceutical Education, 77(8), 171. https://doi.org/10.5688/ ajpe 778171

Macdougall, C. (2017). A novel teaching tool combined with active-learning to teach antimicrobial spectrum activity. American Journal of Pharmaceutical Education, (2), 1

Margolis, A. R., Porter, A. L., \& Pitterle, M. E. (2017). Best Practices for Use of Blended Learning. American Journal of Pharmaceutical Education, 81(3), 1-8. https://doi.org/10.5688/ ajpe81349

Marshall, L.L., Nykamp, D.L., \& Momary, K.M. (2014). Impact of Abbreviated Lecture with Interactive Mini-cases vs Traditional Lecture on Student Performance in the Large Classroom. American Journal of Pharmaceutical Education, 78(10), 189. https://doi.org/10.5688/ajpe7810189

Mclaughlin, J.E., Gharkholonarehe, N., Khanova, J., Deyo, Z.M., \& Rodgers, J.E. (2015). The Impact of Blended Learning on Student Performance in a Cardiovascular Pharmacotherapy Course. American Journal of Pharmaceutical Education, 79(2), 24. https://doi.org/10.5688/ajpe79224

Phillips, J.A., Schumacher, C., \& Arif, S. (2016). Time spent, workload, and student and faculty perceptions in a blended learning environment. American Journal of Pharmaceutical Education, (6)

Pierce, R., \& Fox, J. (2012). Vodcasts and Active-Learning Exercises in a 'Flipped Classroom' Model of a Renal Pharmacotherapy Module. American Journal of Pharmaceutical Education, 76(10), 196. https://doi.org/10.5688/ajpe7610196

Prescott Jr., W.A., Woodruff, A., Prescott, G.M., Albanese, N., Bernhardi, C., \& Doloresco, F. (2016). Introduction and Assessment of a Blended-Learning Model to Teach Patient Assessment in a Doctor of Pharmacy Program. American Journal of Pharmaceutical Education, 80(10), 1-10
Rotellar, C., \& Cain, J. (2016). Research, Perspectives, and Recommendations on Implementing the Flipped Classroom. American Journal of Pharmaceutical Education, 80(2), 1-9. https://doi.org/10.5688/aipe80234

Sancho, P., Corral, R., Rivas, T., González, M. J., Chordi, A., \& Tejedor, C. (2006). A Blended Learning Experience for Teaching Microbiology. American Journal of Pharmaceutical Education, 70(5), 1-9

Shah, S., Cox, A.G., \& Zdanowicz, M.M. (2013). Student perceptions of the use of pre-recorded lecture modules and class exercises in a molecular biology course. Currents in Pharmacy Teaching and Learning, 5(6), 651-658. https://doi.org/10.1016/ j.cptl.2013.07.011

Stewart, D. W., Brown, S. D., Clavier, C. W., \& Wyatt, J. (2011). Active-Learning Processes Used in US Pharmacy Education. American Journal of Pharmaceutical Education, 75(4), 68. https://doi.org/10.5688/ajpe75468

Tatachar, A., Li, F., Gibson, C.M., \& Kominski, C. (2016). Pharmacy students' perception of learning and satisfaction with various active learning exercises. Currents in Pharmacy Teaching and Learning, 8(4), 577-583. https://doi.org/10.1016/i.cptl. $\underline{2016.03 .019}$

Wanat, M.A., Tucker, A.M., \& Coyle, E.A. (2016). A Critical Care Hybrid Online Elective Course for Third-Year Pharmacy Students. American Journal of Pharmaceutical Education, 80(9), 1-7

Wong, T.H., Ip, E.J., Lopes, I., \& Rajagopalan, V. (2014). Pharmacy Students' Performance and Perceptions in a Flipped Teaching Pilot on Cardiac Arrhythmias. American Journal of Pharmaceutical Education, 78(10), 1-6

Zapantis, A., Machado, C., Nemire, R., \& Leung, S. (2008). An Elective Course in Adult Acute Care Medicine Using a Hybrid Delivery System. American Journal of Pharmaceutical Education, 72(5), 1-9

Zorek, J.A., Sprague, J.E., \& Popovich, N.G. (2010). Bulimic Learning. American Journal of Pharmaceutical Education, 74(8), 157. https://doi.org/10.5688/aj7408157 